\title{
MODEL PERAMALAN BEBAN LISTRIK DI KALIMANTAN BARAT DENGAN METODE FUZZY LINEAR REGRESSION
}

\author{
Vina Annisa Nurdiani Aji, Shantika Martha, Nurfitri Imro'ah
}

\begin{abstract}
INTISARI
Listrik merupakan salah satu sumber energi utama yang hampir digunakan pada seluruh aspek kehidupan masyarakat. Peningkatan kebutuhan listrik di masyarakat saat ini mengharuskan PT. PLN (Perusahaan Listrik Negara) perlu melakukan perencanaan operasi dan perencanaan sistem pengembangan tenaga listrik. Hal tersebut diperlukan untuk mengetahui seberapa besar daya listrik yang harus disalurkan ke konsumen agar daya listrik yang ditransmisikan tepat sasaran dan tepat ukuran. Oleh karena itu, diperlukan model peramalan untuk penyesuaian antara pembangkit dan permintaan daya. Banyaknya data merupakan masalah peneliti untuk memodelkan peramalan beban listrik di Kalimantan Barat. Dalam penelitian ini menggunakan metode Fuzzy Linear Regression (FLR) untuk memodelkan peramalan beban listrik di Kalimantan Barat. FLR adalah metode yang dapat memodelkan peramalan dengan himpunan data minimal dua dengan satu variabel independen dan satu variabel dependen. Data yang digunakan dalam penelitian ini sebanyak delapan data dari tahun 2008 sampai dengan tahun 2015 dengan tiga variabel bebas yaitu jumlah penduduk $\left(x_{1}\right)$, jumlah pelanggan $\left(x_{2}\right)$, dan produksi listrik $\left(x_{3}\right)$. Hasil model peramalan beban listrik adalah $\tilde{Y}=(0 ; 58,9939)+(0,0065 ; 0) x_{1}+(0,833 ; 0) x_{2}+$ $(0,5071 ; 0) x_{3}$ dengan nilai hasil ukuran kesalahan model menggunakan MAPE sebesar $1,6804 \%$.
\end{abstract}

Kata kunci: Peramalan, Beban listrik, Fuzzy Linear Regression

\section{PENDAHULUAN}

Listrik merupakan salah satu sumber energi utama yang hampir digunakan pada seluruh aspek kehidupan masyarakat. Pertumbuhan ekonomi, perkembangan dunia industri, pertambahan jumlah penduduk, serta pesatnya kemajuan teknologi merupakan penyebab utama dalam peningkatan jumlah penggunaan listrik di Indonesia. Menurut laporan PT. PLN Wilayah V Kalimantan Barat pada tahun 2015 banyaknya produksi tenaga listrik yang dihasilkan PLN pada 11 lokasi pembangkit mengalami kenaikan sekitar 5,14\% dibanding tahun sebelumnya [1].

Peningkatan kebutuhan listrik di masyarakat saat ini mengharuskan PT. PLN perlu melakukan perencanaan operasi dan perencanaan sistem pengembangan tenaga listrik. Hal tersebut diperlukan untuk mengetahui seberapa besar daya listrik yang harus disalurkan ke konsumen agar daya listrik yang ditransmisikan tepat sasaran dan tepat ukuran. Dengan demikian, kejadian kelebihan maupun kekurangan tegangan dalam sistem tenaga listrik dapat diminimalisasi. Selain itu, dengan efektifitas penyaluran daya dapat meningkatkan pula efektifitas biaya yang harus dikeluarkan PLN untuk biaya ke pihak pembangkitan.

Oleh karena itu, diperlukan metode untuk penyesuaian antara pembangkit dan permintaan daya. Agar penyesuaian tercapai, pihak penyedia listrik harus mengetahui beban atau permintaan daya listrik dengan melakukan perkiraan beban listrik. Beban listrik dapat diperkirakan dengan menerapkan metode Fuzzy Linear Regression (FLR).

Penelitian ini bertujuan untuk menentukan model peramalan beban listrik di Kalimantan Barat dengan metode FLR. Selain itu, mencari ukuran kesalahan model peramalan beban listrik di Kalimantan Barat dengan menggunakan MAPE (Mean Absolute Percentage Error). Dalam penelitian ini, jumlah data yang digunakan sebanyak delapan data dari data tahun 2008 sampai dengan tahun 2015 di Provinsi Kalimantan Barat. Metode FLR adalah metode yang dapat memodelkan peramalan dengan himpunan data kecil. Kemudian metode yang digunakan pada penelitian ini adalah metode FLR dengan data nonfuzzy yang merupakan data yang tidak diubah kedalam bentuk fuzzy [2]. 


\section{REGRESI LINEAR BERGANDA}

Analisis regresi secara konseptual merupakan metode sederhana untuk memeriksa hubungan antara variabel dependen $(Y)$ dan satu atau lebih variabel independen $(X)$. Model regresi linear yang terdiri dari satu variabel independen merupakan model regresi linear sederhana, sedangkan model regresi yang terdiri dari beberapa variabel independen merupakan model regresi linear berganda. Model regresi linier berganda [3]:

$$
Y_{i}=\beta_{0}+\beta_{1} X_{i 1}+\beta_{2} X_{i 2}+\cdots+\beta_{k} X_{n p}+e_{i}
$$

dimana $Y_{i}$ merupakan nilai variabel dependen dalam observasi ke- $i$ dan $X_{i 1}, X_{i 2}, \ldots, X_{n p}$ merupakan variabel independen pada observasi ke-i, dimana $i=1, \ldots, n$ dan $\beta_{0}, \beta_{1}, \beta_{2}, \ldots, \beta_{p}$ merupakan parameter regresi yang tidak diketahui nilainya dan akan dicari nilai estimasinya, $e_{i}$ merupakan galat yang berdistribusi normal dengan mean-nya nol dan variansinya $\sigma^{2}$ atau $e_{i} \sim N\left(0, \sigma^{2}\right)$.

\section{HIMPUNAN FUZZY}

Jika pada himpunan crisp, nilai keanggotaan hanya ada 2 kemungkinan, yaitu 0 atau 1 , pada himpunan fuzzy nilai keanggotaan terletak pada rentang 0 sampai 1 . Apabila $x$ memiliki nilai keanggotaan fuzzy $\mu_{A}(x)=0$ berarti $x$ tidak menjadi anggota himpunan $A$, demikian pula apabila $x$ memiliki nilai keanggotaan fuzzy $\mu_{A}(x)=1$ berarti $x$ menjadi anggota penuh pada himpunan $A$ [4].

Ada beberapa hal yang perlu diketahui dalam memahami sistem fuzzy, yaitu variabel fuzzy dan himpunan fuzzy. Variabel fuzzy merupakan variabel yang hendak dibahas dalam suatu sistem fuzzy seperti umur, temperatur, permintaan. Semesta pembicaraan pada setiap variabel fuzzy merupakan himpunan bilangan real yang senantiasa naik dari kiri ke kanan yang dapat berupa bilangan positif ataupun negatif. Himpunan fuzzy merupakan suatu grup yang mewakili suatu kondisi atau keadaan tertentu dalam suatu variabel fuzzy [4].

Fungsi keanggotaan dari himpunan fuzzy yang digunakan adalah fungsi keanggotaan segitiga [5], seperti terlihat pada Gambar 1.

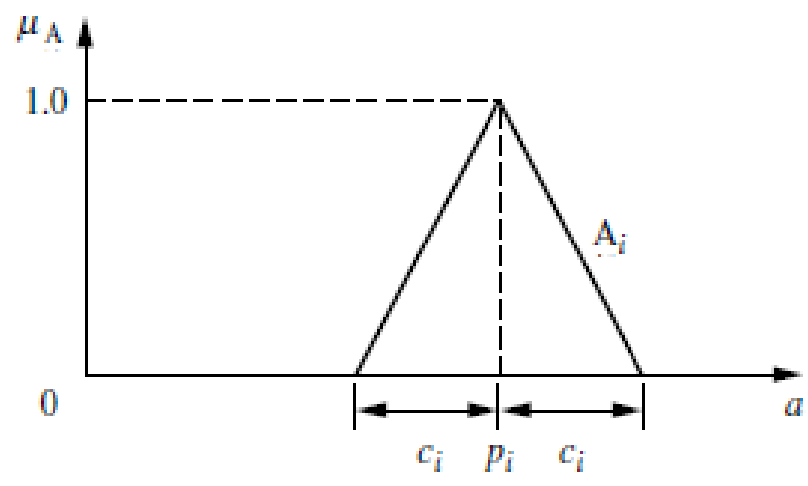

\section{Gambar 1 Fungsi Keanggotaan Segitiga}

Fungsi keanggotaan segitiga:

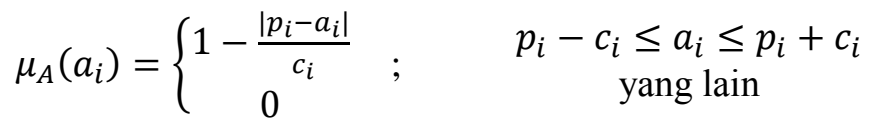

dimana $i=1, \ldots, n$. Fungsi fuzzy $A_{i}$ adalah sebuah fungsi dari dua parameter $p_{i}$ dan $c_{i}$, dimana $p_{i}$ merupakan nilai tengah dan $c_{i}$ merupakan nilai sebaran. Sebaran menunjukkan ketidakjelasan (fuzziness) dari fungsi. 


\section{METODE SIMPLEKS}

Metode simpleks merupakan teknik yang paling baik untuk menyelesaikan masalah program linier yang tidak mempunyai keterbatasan dalam jumlah variabel keputusan dan fungsi kendalanya [6]. Secara umum pemograman linier dapat dirumuskan dalam model dasar, yaitu:

Fungsi tujuan: Maksimasi atau minimasi dari [6]:

$$
Z=c_{1} X_{1}+c_{2} X_{2}+\cdots+c_{n} X_{n}
$$

dengan batasan

$$
\begin{gathered}
a_{11} x_{1}+a_{12} x_{2}+\cdots+a_{1 n} x_{n}(\leq,=, \geq) b_{1} \\
a_{21} x_{1}+a_{22} x_{2}+\cdots+a_{2 n} x_{n}(\leq,=, \geq) b_{2} \\
\vdots \\
a_{m 1} x_{1}+a_{m 2} x_{2}+\cdots+a_{m n} x_{n}(\leq,=, \geq) b_{m}
\end{gathered}
$$

dimana $n$ variabel utama dan $m$ batasan. Dalam metode ini, model diubah kedalam bentuk suatu tabel simpleks, kemudian dilakukan langkah-langkah matematis kedalam tabel tersebut. Metode simpleks bergerak dari satu solusi ke solusi yang lebih baik lagi sampai solusi optimal didapat.

\section{REGRESI LINEAR FUZZY}

Konsep dasar regresi fuzzy yang diusulkan oleh Tanaka (1982) adalah nilai residual antara nilai estimasi dan nilai pengamatan tidak dihasilkan oleh pengukuran error, tetapi oleh parameter yang tidak tetap di dalam model [7]. Model regresi fuzzy dinyatakan sebagai berikut [8]:

$$
\tilde{Y}=f(x, \tilde{A})=\tilde{A}_{0}+\tilde{A}_{1} x_{1}+\tilde{A}_{2} x_{2}+\cdots+\tilde{A}_{n} x_{n}
$$

dimana $\tilde{Y}$ adalah variabel dependen, $x$ adalah variabel independen, $\tilde{A}_{0}$ konstanta, $\tilde{A}_{i}$ menyatakan koefisien fuzzy ke- $i$ dari model dengan $i=1,2, \ldots, n$.

Parameter fuzzy $\tilde{A}=\left\{\tilde{A}_{0}, \tilde{A}_{1}, \ldots, \tilde{A}_{n}\right\}$ dapat dinotasikan dalam bentuk vektornya dengan $\tilde{A}=(p, c)$, dimana $p=\left(p_{0}, \ldots, p_{n}\right)$ dan $c=\left(c_{0}, \ldots, c_{n}\right)$, sehingga Persamaan (5) dapat ditulis menjadi:

$$
\tilde{Y}=\left(p_{0}, c_{0}\right)+\left(p_{1}, c_{1}\right) x_{1}+\left(p_{2}, c_{2}\right) x_{2}+\cdots+\left(p_{n}, c_{n}\right) x_{n}
$$

Dalam regresi fuzzy, untuk meminimalkan sebaran dari fuzzy output, ditunjukkan fungsi objektif yang dinyatakan sebagai berikut:

$$
\text { Minimalisasi } O=\sum_{j=1}^{m} \sum_{i=0}^{n} c_{i} x_{i j}
$$

dimana $x_{0 j}=1$, untuk semua $j=1, \ldots, m$ dengan dua batasan sebagai berikut:

$$
\begin{aligned}
& y_{j} \leq \sum_{i=0}^{n} p_{i} x_{i j}+(1-h) \sum_{i=0}^{n} c_{i} x_{i j} \\
& y_{j} \geq \sum_{i=0}^{n} p_{i} x_{i j}-(1-h) \sum_{i=0}^{n} c_{i} x_{i j}
\end{aligned}
$$

dimana $y_{j}$ merupakan data aktual dari objek ke-j dan derajat nilai $h$ ditentukan oleh peneliti [8]. Nilai $h$ menunjukkan tingkat kekaburan dari parameter fuzzy yang ada dalam model. Kemudian untuk nilai dari variabel dependen dapat diestimasi sebagai bilangan fuzzy (fuzzy number) $\tilde{Y}_{j}=\left(Y_{j}^{L}, Y_{j}^{h}, Y_{j}^{U}\right), j=$ $1,2, \ldots, m$ ditunjukkan oleh persamaan-persamaan berikut:

$$
\begin{aligned}
& Y_{j}^{L}=\sum_{i=0}^{n}\left(p_{i}-c_{i}\right) x_{i j} \\
& Y_{j}^{h}=\sum_{i=0}^{n} p_{i} x_{i j} \\
& Y_{j}^{U}=\sum_{i=0}^{n}\left(p_{i}+c_{i}\right) x_{i j}
\end{aligned}
$$

dimana $Y_{j}^{L}$ merupakan batas bawah interval, $Y_{j}^{h}$ merupakan nilai estimasi, dan $Y_{j}^{U}$ merupakan batas atas interval. 


\section{DATA DAN APLIKASI}

Data yang digunakan pada penelitian ini berupa data sekunder tentang energi listrik tahun 2008 sampai 2015 di Kalimantan Barat yang diperoleh dari situs resmi PLN. Variabel dalam penelitian ini adalah data konsumsi energi listrik, jumlah penduduk, jumlah pelanggan dan produksi listrik di Kalimantan Barat tahun 2008 sampai tahun 2015.

Proses pemodelan peramalan menggunakan FLR meliputi beberapa proses yaitu penaksiran parameter fuzzy, model peramalan, nilai estimasi, ukuran kesalahan model dan analisis hasil [9].

Langkah pertama, substitusikan data kedalam Persamaan (7) kemudian untuk batasannya substitusikan data kedalam Persamaan (8) dengan nilai $h=0,5$. Masalah pemrograman linear ini diselesaikan menggunakan metode simpleks dengan aplikasi POM-QM for windows 3. Hasil perhitungan yang dapat dilihat pada Tabel 1 .

Tabel 1. Nilai Parameter Fuzzy Beban Listrik di Kalimantan Barat

\begin{tabular}{ccccc}
\hline $\boldsymbol{h}$ & $\left(\boldsymbol{p}_{\mathbf{0}} ; \boldsymbol{c}_{\mathbf{0}}\right)$ & $\left(\boldsymbol{p}_{\mathbf{1}} ; \boldsymbol{c}_{\mathbf{1}}\right)$ & $\left(\boldsymbol{p}_{\mathbf{2}} ; \boldsymbol{c}_{\mathbf{2}}\right)$ & $\left(\boldsymbol{p}_{\mathbf{3}} ; \boldsymbol{c}_{\mathbf{3}}\right)$ \\
\hline $\mathbf{0 , 5}$ & $(0 ; 58,9939)$ & $(0,0065 ; 0)$ & $(0,833 ; 0)$ & $(0,5071 ; 0)$ \\
\hline
\end{tabular}

Model peramalan didapat dengan mensubstitusikan nilai parameter fuzzy kedalam model. Berikut model peramalan beban listrik di Kalimantan Barat:

$$
\tilde{Y}=(0 ; 58,9939)+(0,0065 ; 0) x_{1}+(0,833 ; 0) x_{2}+(0,5071 ; 0) x_{3}
$$

Interpretasi dari model tersebut diketahui jika nilai $x_{1}$ (jumlah penduduk) bertambah satu satuan maka nilai $\tilde{Y}$ (peramalan beban listrik) akan bertambah sebesar 0,0065 satuan dengan syarat $x_{2}$ (jumlah pelanggan) dan $x_{3}$ (produksi listrik) konstan. Jika nilai $x_{2}$ (jumlah pelanggan) bertambah satu satuan maka nilai $\tilde{Y}$ (peramalan beban listrik) akan bertambah sebesar 0,833 satuan dengan syarat $x_{1}$ (jumlah penduduk) dan $x_{3}$ (produksi listrik) konstan. Jika $x_{3}$ (produksi listrik) bertambah satu satuan maka nilai $\tilde{Y}$ (peramalan beban listrik) akan bertambah sebesar 0,5071 satuan dengan syarat $x_{1}$ (jumlah penduduk) dan $x_{2}$ (jumlah pelanggan) konstan. Jika $x_{1}$ (jumlah penduduk), $x_{2}$ (jumlah pelanggan) dan $x_{3}$ (produksi listrik) konstan maka nilai $\tilde{Y}$ (peramalan beban listrik) berada pada rentang $0 \pm 58,9939$.

Nilai estimasi dari beban listrik didapat dengan mensubstitusikan nilai $p_{j}$ dan $c_{j}$ yang telah didapat kedalam Persamaan (10). Kemudian untuk batas bawah interval didapat dengan mensubstitusikan nilai $p_{j}$ dan $c_{j}$ yang telah didapat kedalam Persamaan (9). Sedangkan untuk batas atas interval didapat dengan mensubstitusikan nilai $p_{j}$ dan $c_{j}$ kedalam persamaan Persamaan (11), maka diperoleh:

Tabel 2. Nilai Estimasi Beban Listrik di Kalimantan Barat dengan Metode FLR

\begin{tabular}{cccc}
\hline Tahun & Batas Bawah $\left(\boldsymbol{Y}_{\boldsymbol{j}}^{\boldsymbol{L}}\right)$ & Nilai Estimasi $\left(\boldsymbol{Y}_{\boldsymbol{j}}^{\boldsymbol{h}}\right)$ & Batas Atas $\left(\boldsymbol{Y}_{\boldsymbol{j}}^{\boldsymbol{U}}\right)$ \\
\hline 2008 & $1.040,5481$ & $1.099,5420$ & $1.158,5359$ \\
2009 & $1.074,4704$ & $1.133,4643$ & $1.192,4582$ \\
2010 & $1.200,5479$ & $1.259,5418$ & $1.318,5357$ \\
2011 & $1.357,3629$ & $1.416,3568$ & $1.475,3507$ \\
2012 & $1.515,5377$ & $1.574,5316$ & $1.633,5255$ \\
2013 & $1.710,5232$ & $1.769,5171$ & $1.828,5110$ \\
2014 & $1.826,0770$ & $1.885,0016$ & $1.943,9955$ \\
2015 & $1.923,4491$ & $1.982,4430$ & $2.041,4369$ \\
\hline
\end{tabular}


Ukuran kesalahan model peramalan beban listrik dihitung dengan menggunakan MAPE. Hasil ukuran kesalahan model peramalan dapat dilihat pada Tabel 3.

Tabel 3. Ukuran Kesalahan (MAPE) dari Model Peramalan

\begin{tabular}{cccc}
\hline Tahun & $\begin{array}{c}\boldsymbol{x}_{\boldsymbol{t}} \\
\text { (Data Aktual) }\end{array}$ & $\begin{array}{c}\boldsymbol{y}_{\boldsymbol{t}} \\
\text { (Hasil Estimasi) }\end{array}$ & APE \\
\hline 2008 & 1.070 & $1.099,5420$ & 2,7609 \\
2009 & 1.156 & $1.133,4643$ & 1,9495 \\
2010 & 1.289 & $1.259,5418$ & 2,2854 \\
2011 & 1.435 & $1.416,3568$ & 1,2992 \\
2012 & 1.604 & $1.574,5316$ & 1,8372 \\
2013 & 1.740 & $1.769,5171$ & 1,6964 \\
2014 & 1.862 & $1.885,0016$ & 1,2353 \\
2015 & 1.990 & $1.982,4430$ & 0,3797 \\
\hline \multicolumn{5}{c}{} \\
\hline
\end{tabular}

Berdasarkan perhitungan tersebut diperoleh nilai MAPE dari model peramalan menggunakan metode FLR adalah 1,6804\%. Dengan kata lain model beban energi listrik mempunyai kinerja yang sangat bagus dan menunjukkan bahwa ketepatan model peramalan energi beban listrik di Kalimantan Barat menggunakan metode FLR adalah sebesar 98,3196\%. Grafik perbandingan data aktual dengan hasil estimasi ditunjukkan pada Gambar 2.

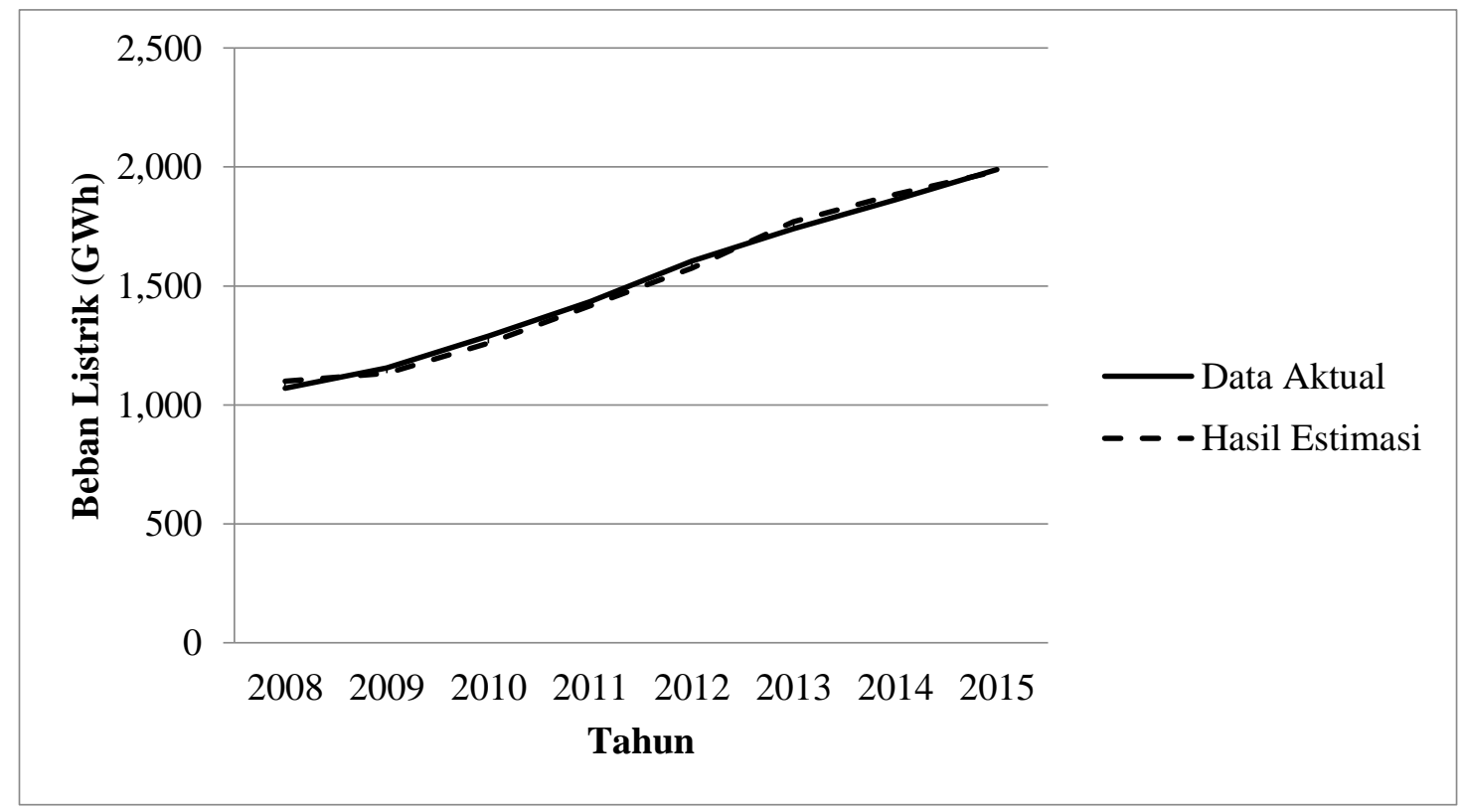

Gambar 2. Grafik perbandingan hasil estimasi dan data aktual

Berdasarkan Gambar 2 dapat dilihat bahwa beban listrik di Kalimantan Barat mendekati data aktualnya yang berarti model peramalan beban listrik di Kalimantan Barat sangat bagus. 


\section{PENUTUP}

Berdasarkan hasil analisa dan pembahasan pada penelitian ini, maka diperoleh kesimpulan model peramalan beban listrik di Kalimantan Barat dengan menggunakan data tahunan dari tahun 2008 sampai dengan 2015 diperoleh model peramalan sebagai berikut:

$$
\tilde{Y}=(0 ; 58,9939)+(0,0065 ; 0) x_{1}+(0,833 ; 0) x_{2}+(0,5071 ; 0) x_{3}
$$

Hasil ukuran kesalahan model FLR dengan menggunakan MAPE adalah 1,6804\% menunjukkan bahwa ketepatan model peramalan energi beban listrik di Kalimantan Barat menggunakan metode FLR adalah sebesar 98,3196\%. Dengan kata lain model beban energi listrik mempunyai kinerja yang sangat bagus.

\section{DAFTAR PUSTAKA}

[1] Badan Pusat Statistik Kalimantan Barat. Diakses 15 September 2016, dari http://kalbar.bps.go.id.

[2] Ni, Y., 2005. Fuzzy Correlation and Regression Analysis. Oklahoma: UMI

[3] Chatterjee, S., Hadi, Ali S., 2006. Regression Analysis by Example. Edisi ke-4. New Jersey: John Wiley \& Sons, Inc

[4] Kusumadewi, S., Purnomo,H., 2010. Aplikasi Logika Fuzzy. Yogyakarta: Graha Ilmu

[5] Rozaq, Abdul., 2012. Regresi Linier Fuzzy Pada Data Time Series. Gamatika, 3:23-32

[6] Puryani, Ristono A., 2011. Penelitian Operasional. Yogyakarta: Graha Ilmu.

[7] Putra, D.D., 2014. Aplikasi Metode Fuzzy Linear Regression (FLR) sebagai Alat Peramalan. Jurnal Matematika, F.MIPA, Universitas Brawijaya

[8] Ross, T. J., 2004. Fuzzy Logic With Engineering Application. Edisi ke-2. Chicester: John Wiley \& Sons, Ltd

[9] Purwareta,H. P., Usadha, I. G., dan Wahyuningsih, N., 2012. Model Peramalan Pasokan Energi Primer Dengan Pendekatan Metode Fuzzy Linear Regression(FLR).Jurnal Sains Dan Seni ITS, $1: 34-39$

$\begin{array}{ll}\text { VINA ANNISA NURDIANI AJI } & \begin{array}{l}\text { Jurusan Matematika FMIPA UNTAN, Pontianak, } \\ \text { viannis94@gmail.com }\end{array} \\ \text { SHANTIKA MARTHA } & \text { Jurusan Matematika FMIPA UNTAN, Pontianak, } \\ \text { shantika.martha@ @math.untan.ac.id } & \text { : Jurusan Matematika FMIPA UNTAN, Pontianak, } \\ \text { nurfitriimroah18@gmail.com }\end{array}$

